\title{
AVALIAÇÃO ESTRATÉGICA COM BASE EM VALORES ORGANIZACIONAIS NA PRESTAÇÃO DE SERVIÇOS
}

\author{
Tiago Dantas Sebastião da Silva ${ }^{1}$
}

\begin{abstract}
RESUMO: Avaliação é uma atividade que envolve uma analise profunda de elementos importantes em determinado processo, uma observação analítica para elaboração de um diagnóstico que possibilite o entendimento dos fenômenos e fatos que interferem, positivamente e negativamente, na tomada de decisões. Atrelado a avalição podemos utilizar estratégias que viabilizem a tomada de decisão na Prestação de Serviços, ou seja, "aplicando e explorando maneiras disponíveis de condições favoráveis com vistas à consecução de objetivos específicos". Os Valores Organizacionais são vistos como princípios e crenças compartilhados pelos empregados e quando analisados estrategicamente orientam o funcionamento e a vida da organização, de forma a alcançar a meta da mesma. A vista disso procura-se observar quatro fatore viabilizam essa avaliação: (I) fator de apoio a decisão, possibilita a redução da incerteza e permite escolhas com menor risco e no momento adequado; (2) fator de produção ou operacional, permite criar e introduzir no mercado produtos ou novas técnicas (bens ou serviços) de maior valor adicionado; (3) fator de sinergia, condicionado a qualidade das ligações e relações entre seus membros internos e externos;(4) fator determinante de comportamento, elementos que exercem influência sobre o comportamento dos indivíduos e dos grupos e consequentemente afetam o processo organizacional. Desta forma, o presente artigo tem como objetivo orientar as organizações para desenvolvimento de ferramentas qualitativas e quantitativas de analise dos valores organizacionais na prestação de serviços, bem como, a importância de avaliar estrategicamente, utilizando essas ferramentas para compreensão e melhoria dos processos organizacionais.
\end{abstract}

Palavras-Chave: Avaliação Estratégica. Avaliação Qualitativa e Quantitativa. Valores Organizacionais. Prestação de Serviços.

ABSTRACT: Assessment is an activity that involves a thorough analysis of important elements in a given process, an analytical observation to make a diagnosis that allows the understanding of phenomena and events that affect, positively and negatively, in decision-making. Linked to appraisal can use strategies that enable decision making in providing services, ie, "applying and exploring available ways of favorable conditions in order to achieve specific objectives". The Organizational Values are seen as principles and beliefs shared by the employees and when analyzed strategically guide the operation and life of the organization, in order to achieve the goal of it. The view also seeks to observe four factors enable this evaluation: (I) factor support the decision, allows the reduction of uncertainty and allows choices with less risk and at the right time; (2) factor production or operational, lets you create and market products and new techniques

\footnotetext{
' Tutor EaD no Grupo Ser Educacional / Bacharel em Administração de Empresas pela Faculdade de Ciências Humanas e Sociais de Igarassu (FACIG) / Tecnólogo em Gestão de Sistemas de Informação pela Universidade Paulista (UNIP) / Pós-graduação: MBA em Gestão Estratégica de Pessoas pela Faculdade de Ciências Humanas Esuda / Pós-graduando em Metodologia do Ensino à Distância pela Universidade da Amazônia (UNAMA) / E-mail: tiagodantaszo@hotmail.com
} 
(goods or services) of greater added value; (3) synergy factor, conditioning the quality of links and relations between internal and external members; (4) determining factor of behavior, elements that influence the behavior of individuals and groups and consequently affect the organizational process. Thus, this article aims to guide organizations to develop qualitative and quantitative tools of analysis of organizational values in providing services as well as the importance of strategically evaluate, using these tools to understand and improve organizational processes.

Keywords: Strategic Assessment. Qualitative and Quantitative Evaluation. Organizational Values. Provision of Services.

\section{INTRODUÇÃO}

O planejamento, o controle, a avaliação e a utilização de ferramentas que auxiliem o processo de tomada de decisão e operacional dentro das organizações tornam-se cada dia um diferencial estratégico e competitivo. Tão importante quanto produzir, vender e lucrar é avaliar, ou seja, coletar, organizar, combinar e equacionar dados, gerando informações referentes ao processo de serviços prestados e transformá-los em conhecimento, considerado hoje como "o ativo de produção mais importante, diante dos ativos tradicionais de mão de obra, capital e tecnologia"(JOÃO, 200o, p.46). Através disso, seremos capazes de produzir inovações e avaliarmos se estamos evoluindo, bem como garantir a sobrevivência das organizações no mercado. A combinação e análise das duas vertentes, qualitativa e quantitativa, singulares e ao mesmo tempo complementares, visam contemplar itens valorizados pelo cliente e pelas organizações na prestação dos serviços, cada um com suas características, o que se pode chamar de cultura, crenças, valores e costumes que orientam a interação entre as pessoas, os objetivos individuais e os objetivos organizacionais e sua influência no processo, de maneira a utilizar os atributos de influência próprios, que se destaca sobre a melhor forma de atuação.

Esta abordagem pode apresentar perspectivas diferentes, proporcionando a otimização das atividades internas e externas em tamanho e importância dos negócios relacionados ao setor de serviço, que tem se tornado fundamental para a economia. $O$ desenvolvimento de modelos e métodos é a diretriz básica dessa avaliação, e varia de acordo com necessidades gerais e/ou especificas dos serviços de acordo com o segmento, pois isso determina se estamos próximos aos padrões fundamentais ajustados à realidade que vivemos de forma a assegurar resultados mais consistentes e adequados à situação atual. 
A identificação dos elementos e a mensuração são a base técnica de análise, associados às ações e aos resultados do processo produtivo e/ou operacional, não baseados em subjetivismos, mas, em elementos bem definidos e precisos, contribuindo para o perfeito entendimento de forma continua e evolutiva.

A avaliação estratégica implica no somatório de todas essas atividades, desenvolvimento de modelos, métodos, mensuração e a identificação dos indicadores, com base na característica do serviço prestado, analisando todas as variáveis que influenciam este no momento de sua prestação, pois quando combinados, proporcionam conhecimento e a influência de modo que as informações obtidas das atividades deste somatório de elementos envolvidos, positiva ou negativa, direcionem na busca da capacidade de gerar qualidade e dinamicidade contínua, viabilizando melhorias e direcionando para inovações essenciais no atual mercado competitivo.

Esta pesquisa caracteriza-se em uma revisão da literatura por tratar de um processo de investigação que envolve localizar, analisar, sintetizar e interpretar os dados de diversas fontes de conhecimento relacionados ao tema da pesquisa (revistas científicas, livros, resumos, artigos, etc.), buscando retomar os discursos de outros pesquisadores e estudiosos, reconhecendo a contribuição dos mesmos, bem como interagir com eles por meio de análise e categorização, a fim de evidenciar a relevância da pesquisa realizada.

O tipo de metodologia utilizada para realização da pesquisa é a revisão da literatura narrativa ou tradicional, permite uma temática mais aberta em seu desenvolvimento e com menos rigidez. Porém, a seleção dos artigos é arbitrária, provendo informações sujeitas ao viés de seleção do seu autor, com grande interferência da percepção subjetiva, todavia, direcionando para resultados objetivos por ter como escopo central o levantamento e a avaliação dos valores organizacionais mais representativos e relevantes para o diagnóstico da cultura da empresa.

Possui uma abordagem Interdisciplinar, por agrupar e agregar vário outros saberes, que recorre a informações de vários conhecimentos para analise de um determinado elemento, nesse caso, a temática proposta, com a preocupação de interligar os saberes entre si. Assim, cada conhecimento/ciência contribui com informações próprias do seu campo de conhecimento, considerando que existe uma integração entre elas. É um tipo de saber específico, que possui um objeto determinado e reconhecido, com conhecimentos e saberes 
relativos a esse objeto e métodos próprios. Possibilita obter uma visão mais holística, mais integrada do conhecimento disponível e das várias conexões entre os elementos, combinando estes para compor uma alternativa ou hipótese mais favorável e inovadora.

Por fim, corresponde a um compendio de citações que analisa a importância da “Avaliação Estratégica com Base em Valores Organizacionais na Prestação de Serviços”, com o objetivo de compreender os desafios enfrentados na Gestão de Pessoas e os processos ligados a esta, partindo do pressuposto de que as organizações vivem em um ambiente dinâmico e necessita de uma avaliação constante para uma boa gestão de suas atividades.

\section{SERVIÇOS NAS ORGANIZAÇÕES}

"Um serviço é uma experiência perceptível, intangível, desenvolvida para um consumidor que desempenha o papel de coprodutor"

(James Fitzsimmons)

Presenciamos hoje uma migração da mão de obra desde a revolução industrial, impulsionadas pelas comunicações globais, pelo crescimento dos negócios e desenvolvimento tecnológico. Os setores de serviços são líderes em todas as nações industrializadas, gerando empregos, melhorando potencialmente a qualidade dos negócios e satisfazendo cada vez mais seus usuários. Além disso, a atividade econômica de uma sociedade determina a forma como vive a sua população e como é mensurado o seu padrão de vida.

Nos anos 1950 fazia-se a apologia da venda como a grande competência das empresas industriais, mas isso se tornou insuficiente para o mercado competitivo de hoje. $O$ foco transferiu-se de vender para servir. Tanto as empresas produtoras de bens quanto as que prestam serviços procuram oferecer novas soluções para os seus clientes, disputando-lhes a preferência ao agregar valor às suas ofertas.

Podemos encontrar várias definições, porém, todas consideram a intangibilidade e o consumo simultâneo, em diferentes graus, como características de serviços. Alguns conceitos representam uma amostra das definições de serviços apresentados por Fitzsimmons: 
Serviços são atos, processos e o desempenho das ações. (Valerie A. Zeithaml e Mary Jo Bitner, Services Marketing, MacGraw-Hill, New York, I996, p. 5.)

Serviço é uma atividade ou uma série de atividades de natureza mais ou menos intangível que normalmente, mas não necessariamente, ocorre em interações entre consumidores e empregados de serviços e/ou recursos físicos ou bens e/ou sistemas de fornecedores do serviço, que são oferecidos como soluções para os problemas do consumidor. (Christian Gronroos, Service Management and Marketing, Lexington Books, Lexington, Mass, 1990, p. 27)

Os serviços são atividades econômicas oferecidas por uma parte a outra, considerando frequentemente desempenhos com base em um período de tempo para provocar resultados desejados nos próprios usuários, em objetos ou em outros bens pelos quais os compradores são responsáveis. Em troca pelo seu dinheiro, tempo e esforço, os clientes de serviços esperam obter valor com o acesso a bens, mão de obra, capacidades profissionais, instalações, redes e sistemas; mas normalmente eles não possuem nenhum dos elementos físicos envolvidos. (Christopher Lovelock e Lauren Wright, Service Marketing: People, Technology, Strategy, 6th Ed., Upper Saddle River, NJ; Prentice-Hall, 2007, p. 6.)

A prestação do serviço apresenta algumas características: participação do cliente no processo; simultaneidade; perecibilidade; intangibilidade e heterogeneidade. A primeira diz respeito à presença ativa do cliente, tornando-se coautor do processo. $\mathrm{Na}$ segunda, os serviços são criados e consumidos simultaneamente, por isso a impossibilidade de serem estocados. Terceiro, pelo fato de não poder ser estocados, se não forem usados em sua potência ou capacidade total, estão perdidos para sempre. Quarta, algo que não é palpável, diferente de um produto que podemos pegar e sentir antes de usá-lo, os serviços precisam conquistar a confiança através da reputação da organização prestadora, para então serem usados, porém, os resultados só podem ser avaliados após a sua conclusão; por último a heterogeneidade, pois variam de acordo com o consumidor devido a características especificas deste.

Ao falarmos em serviços, estamos falando em interação de funcionários e clientes em tempo real, e funcionário e organização, com todos os aspectos comportamentais e psicológicos que isso envolve: confiança, atitude, proatividade, interesse, acolhimento, consideração, troca, cooperação e compreensão, etc., que podem variar bastante em preço e qualidade, dependendo de onde, quando e por quem são prestados. Todo conjunto interno e externo de circunstâncias que afetam o resultado diretamente em diferentes desempenhos cada vez que é repetida.

Fitzsimmons (20I0) afirma que a natureza dos serviços está em transformação, passando de transacional para relação baseada em experiências, considera que a economia 
da experiência em serviços foi dividida em duas, serviço ao consumidor e serviços empresariais, experiência esta que envolve e estabelece relações de uma maneira mais pessoal e memorável criando valor agregado aos negócios, entende-se que é fundamental fazer a distinção entre insumos e recursos. O primeiro são os consumidores, e o segundo, são os bens facilitadores, a mão de obra dos colaboradores e o capital sob o comando do gestor ou proprietário. Combinar a capacidade do serviço com a demanda, e com base nisso organizar informações para análise e avaliação de forma a tomar decisões estratégicas, é um desafio, preocupando-se sempre em compor uma prestação de serviço eficiente e efetiva.

Por isso, faz-se necessário o desenvolvimento de modelo estratégico, novos métodos de agregar valor na prestação de serviço, dentro da realidade de mercado, avaliando constantemente os elementos presentes em todas as atividades direta e indiretamente ligadas ao processo, e com isso sair na frente da concorrência.

\section{A IMPORTÂNCIA DA AVALIAÇÃO ESTRATÉGICA NAS ORGANIZAÇÕES}

“...o fato é que toda avaliação deve ser desenvolvida com base em informações que permitam caracterizar efetivamente todo esse cenário (relações internas e externas)."

(Edson Pacheco Paladini)

A avaliação é uma estratégia utilizada para investigar e identificar dados e informações referentes a um conjunto de atividades especificas, com a finalidade de medir e oferecer ao seu usuário uma visão da situação avaliada que possibilite entender melhor o ambiente (interno ou externo), o processo e as atitudes relevantes. Requer uma análise das comparações e observação dos padrões, executada de maneira simples e bem clara, concentrando-se em pontos chaves. Em geral, os mecanismos de avaliação estão associados a pontos bem determinados da atividade principal na prestação de serviços, pois medem algumas variáveis qualitativas, atribuindo um grau de importância de maneira quantitativa dando forte relevância ao fato, fornecendo resultados confiáveis, claramente caracterizados, tentando entender seus impactos dentro do processo da prestação de serviço e no clima organizacional. 
Existem alguns elementos básicos segundo Paladini (20II) para os quais a avaliação direciona suas ações:
a. Consumidores e clientes;
b. Objetivos da empresa (organização);
c. Processo;
d. Recursos humanos; e
e. Suporte ao processo.

Desses elementos citados, considera-se estratégico (consumidores e clientes; objetivos da empresa), é considerado operacional (processo), e dois interagem na Gestão Tática da Qualidade (recursos humanos e suporte ao processo).

\section{I Elementos Estratégicos para Avaliação}

a. Consumidores e clientes - consumidores utilizam o serviço, os esforços são direcionados para que tenham multiplicidade de elementos na prestação do serviço, onde a avaliação procura identificar o nível de satisfação com base em valores já conhecidos. E clientes são aqueles que poderão utilizar ou não, os esforços são direcionados para a melhora contínua dos serviços, de maneira a atrair o cliente para que este se torne um consumidor, definindo um perfil de atendimento que será conferido, identificando elementos possíveis de avaliar.

b. Objetivos - procura avaliar a eficiência dos serviços prestados, os elementos que envolvem objetivos individuais e os objetivos organizacionais impulsionam a todos os envolvidos a manifestarem esforços elevados para atender aos interesses simultaneamente.

\subsection{Elementos Operacionais da Avaliação}

a. Processo - é a avaliação mais simples por se utilizar medições diretas de desempenho, avalia quantitativamente e qualitativamente ações em todo processo ou parte dele. Paladini (2oII) destaca que a avaliação do processo engloba três elementos básicos: (a) eliminação de perdas; (b) otimização do processo; e (c) inserção da avaliação do processo nos objetivos globais da organização. E através desses elementos são definidos o conjunto de procedimentos, com base em quatro 
características: (a) atividades típicas; (b) natureza das atividades; (c) prioridades; e (d) direcionamento.

\subsection{Elementos Táticos da Avalição}

a. Mão de Obra - a avaliação leva em conta a relação entre (I) o que a organização requer da mão de obra, tais como: competência, motivação, aceitação e conformidade com os objetivos organizacionais e (2) o que a mão de obra necessita da organização, considerando aspectos culturais e comportamentais, que envolvem investimento em formação, qualificação e atualização, dentre outros, todavia, ajustadas a realidade dos colaboradores.

b. Suporte ao Processo - tem foco no desempenho prestado e como este contribui nos setores com os quais interagem com a atividade-fim a que se destinam, analisando as partes que individualmente (ação-meio) que contribuem para um resultado coletivo (ação-fim).

A Avaliação Estratégica deve centrar-se na integração desses elementos, o que chamamos de modelo Holístico, pois permite uma analise de longo alcance, não há um

método considerado mais ou menos viável, todavia, deve-se avaliar o impacto dos elementos que interagem entre si para atingir dados objetivo global. Nessa perspectiva, existem duas abordagens metodológicas para avaliação de característica global, a qualitativa e a quantitativa.

\section{MÉTOdO (QUALITATIVO E QUANTITATIVO)}

"Não há só um método para estudar as coisas."

(Aristóteles)

Podem-se utilizar dois métodos bastante conhecidos, o qualitativo que busca identificar a presença ou não de certo atributo ou objeto no fenômeno sendo observado, estabelecendo padrões de comportamento verificados através de fatos observáveis, enquanto o quantitativo procura mensurar tal atributo, medindo seu grau de presença ou atuação estabelece padrões de comportamento que possam ser medidos através de números. 


\section{I Qualitativo}

Qualidade é sempre definida por variáveis específicas, caracterizada por diversas expectativas assumindo significados relevantes. A Avaliação Estratégica Qualitativa compreende o uso de técnicas interpretativas de um sistema complexo de significados subjetivos, através da obtenção de dados descritivos pelo contato direto e interativo com a situação objeto de análise de interesse, pois procura entender os fenômenos segundo a perspectiva dos envolvidos na situação de análise, possibilitando o estímulo ao desenvolvimento de novas compreensões aos fenômenos ligados ao processo de prestação de serviço, buscando trazer respostas em relação aos comportamentos, motivos e emoções dos indivíduos, grupos ou organizações que agem de acordo com seus valores, sentimentos e experiências, estabelecendo relações internas próprias, apresentando diversas alternativas dentro de um ambiente mutável com aspectos culturais, econômicas, sociais e históricas que não são passíveis de controle e sim de difícil interpretação, porém explicáveis.

Segundo Avedis Donabedian (1990), a avaliação qualitativa está ancorada em dados quantitativos, o mesmo destaca sete pilares da qualidade: (I) otimização - usar os recursos da melhor maneira possível, (2) eficiência - menor custo a ser aplicado, (3) eficácia - fazer o melhor nas condições mais favoráveis, (4) efetividade - ações cotidianas em condições alcançáveis, (5) equidade - justa na distribuição, (6) legitimidade - total conformidade para o individuo e sociedade, e (7) aceitabilidade adaptável aos desejos, expectativas e valores.

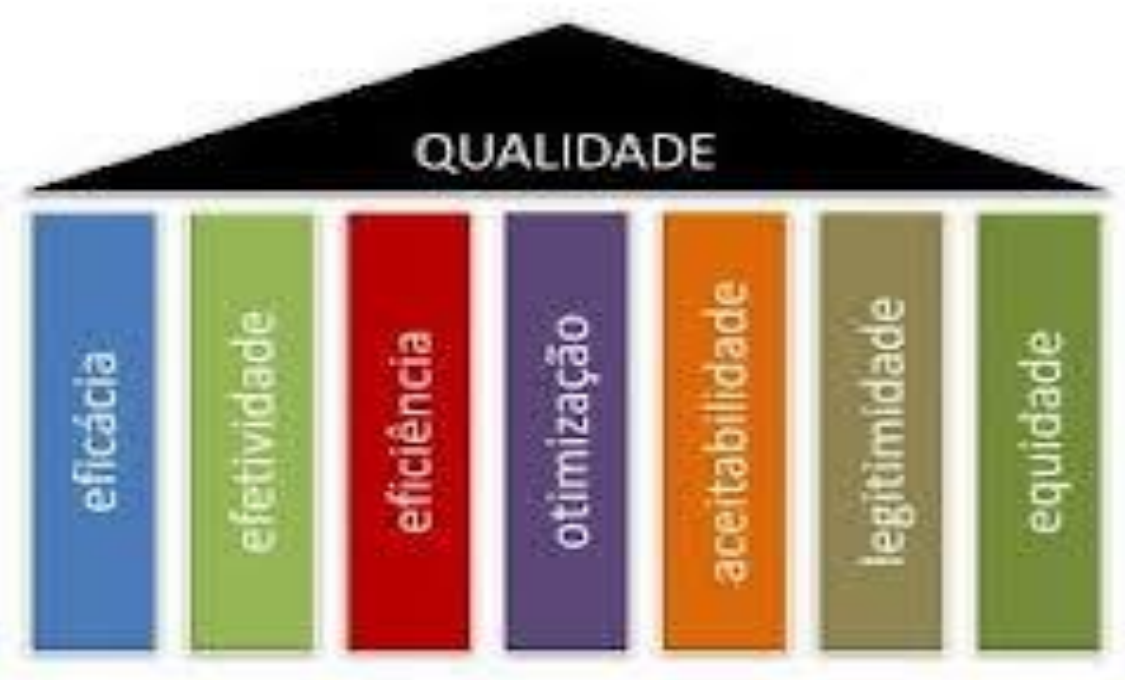

Fonte: Donabedian (1990) 


\subsection{Quantitativo}

A Avaliação Estratégica Quantitativa tem como característica fundamental a mensuração de opiniões, reações, hábitos e atitudes em um universo de eventos, que o represente estatisticamente através de uma amostra, preocupam-se em medir quantidade, quantas vezes ocorrem determinado evento ou fato, frequência, o número de vezes que ocorre, tem um significado específico e intensidade, se sua influência foi ou é forte ou fraco, com base nessas informações realizar uma analise profunda e minuciosa das relações causais entre as variáveis. Identifica, quantifica e reporta os resultados das atividades nas respectivas áreas de responsabilidade com base nas características desejadas, diagnosticando os resultados operacionais do serviço prestado, apurando sua contribuição e reconhecendo o valor e influência de uma ou várias características aumentando ou diminuindo à medida que o mercado atribui maior ou menor importância a cada valor específico, de acordo com a natureza da organização e com a utilidade que proporciona à mesma, sujeito a um critério próprio, que reflete o potencial do serviço em determinado momento.

\subsection{Triangulação}

Terence (2006) e Escrivão Filho (2006) em seu artigo "Abordagem quantitativa, qualitativa e a utilização da pesquisa-ação nos estudos organizacionais”, trazem uma definição clara e objetiva sobre a triangulação de métodos, enfatizam com base em vários pesquisadores que se refere à:

Comparação de dados coletados por abordagens quantitativas e qualitativas, ou seja, diz respeito a adotar métodos diversos para a análise de uma única questão ou objeto de estudo. Pode ser utilizada com a combinação alternada ou a utilização simultânea dos dois métodos para responder à questão de pesquisa. Portanto, as abordagens podem ser complementares e adequadas para minimizar a subjetividade e aproximar o pesquisador do objeto de estudo, respondendo às principais críticas das abordagens qualitativa e quantitativa, respectivamente, proporcionando maior confiabilidade aos dados. (GODOY, 2005; HAYATI; KARAMI; SLEE, 2006; PATTON, 2002).

\subsection{Quando utilizar a abordagem quantitativa e/ou qualitativa}

Para saber o melhor momento de utilizar essas duas abordagens Tanaka (2006) e

Melo (2006), apresentam oito características para cada abordagem a ser observada para a 
efetiva incorporação da avaliação. Os mesmos defendem a implantação de programas mais racionais e efetivos como um instrumento fundamental de gestão com base critérios da figura abaixo.

\begin{tabular}{|l|r|l|}
\hline \multicolumn{1}{|l|}{ QUANDO UTILIZAR A ABORDAGEM } \\
QUANTITATIVA
\end{tabular} \mid \begin{tabular}{l} 
QUANDO UTILIZAR A ABORDAGEM QUALITATIVA \\
\hline 1.
\end{tabular}

Fonte: Tanaka, Oswaldo Y. (2006); Melo, Cristina (2006)

\section{MENSURAÇÃO}

$$
\begin{gathered}
\text { "Se algo não pode ser medido, ele realmente não existe." } \\
\text { Willian Thompson - Lorde Kelvin (1824-1907) }
\end{gathered}
$$

Mensurar é uma atividade inerente ao ser humano, pois está presente em todos os ambientes da sua vida. Medir fatores e atributo é dar significado à complexidade dos fenômenos naturais inerentes ao processo. Medir faz parte da rotina administrativa de toda organização e de sua interação com o público interno e externo. Para que se possam realizar medições, é de fundamental importância a existência de métricas e instrumentos de trabalho adequados.

Mensurar, medir, realizar medição, ou seja, é determinar o valor de certas grandezas. Essa expressão é usada em diversas áreas da ciência tais como: na Medicina e Antropologia, onde a mensuração é caracterizada pela determinação de dimensões 
(mensuração da pressão, do nível de glicemia, da intensidade da dor, etc.) ou para definir a medida de determinados pontos anatômicos localizados (por exemplo, mensuração da gordura corporal através das dobras cutâneas); na Contabilidade, que procura medir os ativos e passivos, atribuir valores monetários aos elementos que compõem o patrimônio; na Administração de Empresas, medir os resultados e o desempenho, refere-se principalmente à forma de avaliação da atuação do funcionário nas suas atribuições dentro da empresa e sua influência com os clientes. A mensuração de resultados pode ser feita através de diferentes instrumentos, esse último é que queremos enfatizar.

Medir objetos e eventos não é apenas uma necessidade científica, mas é dar significado à complexidade dos fenômenos naturais. (Revista Digital de Biblioteconomia e Ciência da Informação, Campinas, v. 3, n. I, p. 6o-76, jul./dez. 2005 - ISSN:: 1678-765X) Helen Beatriz Frota Rozados

Três fatores são fundamentais de acordo com Geisler (200o) no processo de mensuração: a cultura da organização; um conjunto disponível de métricas e o tipo de atividade a ser medida; e outras influências, como os atores envolvidos (comunidade científica e de negócios ou interesses governamentais). Para o mesmo, três aspectos trazem a definição de métrica, são estes: o item medido (o que medir), a unidade de medida (como medir) e o inerente valor associado com a métrica (por que medir ou o que se pretende encontrar com esta mensuração).

Desta maneira, com base nas afirmações apresentadas, procura-se traçar algumas considerações, partindo da abordagem de Guerreiro (1989, p.93) que nos apresenta as etapas básicas fundamentais para a mensuração, direcionadas para o conceito de gestão econômica, todavia, com algumas pequenas modificações aplicadas as organizações em geral sem alterar seu objetivo principal do autor acima citado. São elas:

a) Identificar o tipo de decisão a ser tomada: o tipo de decisão a ser tomada define a informação a ser obtida e como serão mensurados os seus elementos componentes. Muitas vezes é preciso adotar critérios de mensuração diferentes a fim de se fornecer alternativas de decisão aos usuários de acordo com cada variável levantada;

b) Identificar o sistema relacional empírico: identificar o conjunto de objetos e eventos que serão mensurados. Trata-se de identificar as propriedades empíricas 
desses objetos e eventos, que os tornam comparáveis com objetos da mesma natureza;

c) Identificar a característica de interesse da medição: a característica de interesse da medição é ditada pelo modelo decisório dos usuários. A informação precisa identificar-se com a decisão que subsidiará.

d) Identificar a unidade de mensuração: a mensuração será feita por quantidade, frequência, grau de importância, dentre outros, ou seja, determinado padrão escolhido para mensuração da relação adotada que lhe atribuem grandezas;

e) Definir a base conceitual (critérios de mensuração): uma vez que as organizações usam a mensuração feita basicamente por eventos e elementos específicos, deve-se estabelecer a base conceitual dessa mensuração.

f) Identificar o sistema relacional numérico: os números relacionados aos objetos ou eventos precisam ter significado; é preciso evidenciar a escala ou unidade de mensuração a ser utilizada;

g) Analisar o sistema de mensuração caracterizado, à luz do purpose view (informação adequada) e do factual view (confiabilidade, validade, tipo de escala $e$ significado numérico): a mensuração deve ser feita tendo em mente fornecer a informação correta, na hora exata. E por informação correta entende-se aquela que atende às quatro características do factual view, acima relacionadas. Se considerado o item " $a$ " antes apresentado, em conjunto com o item “c”, à luz do item "g", fica claro que não há como se criar um modelo único de mensuração aplicável para todas as organizações. Muitas vezes é difícil aplicar um mesmo modelo em mais de uma organização, por mais parecidas que sejam. O que se tem são conjuntos de conceitos reunidos conforme certas abordagens ou certas fundamentações, e que serão utilizados de acordo com a condição e necessidade de cada organização.

\section{I INDICADORES}

"Só se pode entender o sistema de chuvas observando-se o conjunto, não apenas uma das partes."

(Peter M. Senge)

O termo "indicador", como ferramenta de gestão, é a medida que indica uma tendência do que está acontecendo com base em parâmetros quantificados ou qualitativos 
que servem para detalhar se os objetivos de uma determinada organização estão sendo alcançados, diz respeito à avaliação de processos, relacionados à avaliação de resultados, onde são obtidas informações por meio de comparações e análise de situações inerentes a prestação de serviços, com metas pré-determinadas pela organização nos seus diversos setores, apresentando uma série de características que se complementam.

Segundo Paladini (2011, p.27), indicadores são "mecanismos de avaliação formulados em bases mensuráveis, ou seja, são expressos de forma quantitativa. Os indicadores, assim, são sempre definidos por números, isto é, em valores associados a escalas contínuas.”

Rozados (2005) em seu artigo "Uso de Indicadores na Gestão de Recursos da Informação" define indicadores assim:

[...] de acordo com a OCDE, organização internacional com reconhecidas e adotadas publicações sobre o assunto, em uma definição clássica (OCDE, 200I), especifica que indicadores são "[ . . ] uma série de dados definidos para responder perguntas sobre um fenômeno ou um sistema dado". A International Standart Organization (ISO) estabelece que indicadores são: "Expressão (numérica, simbólica ou verbal) empregada para caracterizar as atividades (eventos, objetos, pessoas), em termos quantitativos e qualitativos, com o objetivo de determinar o valor" (ISO, 1998, p. 3)."

Rozados (2005, p. 65 e 66) ainda apresenta os quatro critérios de Sutter (2002) para a escolha dos indicadores:

O primeiro refere-se à pertinência, ou seja, um indicador deve ser fiel, deve estampar uma imagem fiel de um fenômeno estudado, com o mínimo de distorção; deve ser justo ou estável, o que significa dar uma informação exata e renovável, e também deve ser preciso ou sensível, indicando que as variações significativas do fenômeno precisam ser refletidas pelas variações coerentes do indicador. $O$ segundo refere-se ao caráter operacional, no qual um indicador deve ser fácil de estabelecer, fácil de utilizar, vendável ou aceitável, ou seja, não deve ser contrário à cultura dos destinatários; deve, também, ser comunicante, o que significa permitir o diálogo entre diferentes populações. Como terceiro critério cita o caráter consolidável (agregável) que se refere ao fato de que um indicador deve ser confiável, consolidável, agregável ou acumulável, ou seja, sua consolidação facilita as análises e as sínteses anteriores e permite deixar em evidência as tendências, enquanto durem. O último aspecto diz respeito ao caráter econômico, que significa que um indicador deve ser calculável monetariamente ou ser útil à prevenção."

Para conclusão sobre os indicadores Rozados (2005, p.66) afirma: 
Percebe-se, em nível mundial, que é cada vez mais crescente o incentivo pela busca da qualidade total nas unidades de informação, fazendo com que aumente a preocupação com a definição e a utilização de indicadores apropriados, que auxiliem na avaliação e na gestão destes serviços. Os indicadores de desempenho, por medirem eficiência e eficácia, fatores que estão diretamente ligados à satisfação do usuário-cliente, têm sido os escolhidos por unanimidade, entre os autores e pesquisadores do tema. Concorda-se com esta escolha por se crer que o fim maior da gestão da qualidade é a satisfação do usuário-cliente e que a excelência desta satisfação só pode ser alcançada através de serviços eficientes e eficazes. Por outro lado, a busca pela excelência exige o sistemático levantamento de dados e informações, com a finalidade não somente de avaliar os serviços, mas, principalmente, utilizá-los como elementos do planejamento estratégico. Nesta perspectiva, entendem-se indicadores de desempenho como uma ferramenta para mensurar a satisfação do usuário e a qualidade dos serviços, com vistas à avaliação e à tomada de decisão.”

\section{VALORES ORGANIZACIONAIS}

“...se basearmos nossa vida em valores, qualquer ato valerá a pena”

(Ken O’Donnell)

Tamayo (1998) define que a palavra valor diz respeito à oposição que o ser humano estabelece entre o principal e o secundário, entre o essencial e o acidental, entre o desejável e o indesejável, entre o significante e o insignificante. Para ele, valor representa a ausência de igualdade entre as coisas, os fatos, os fenômenos ou as ideias. Os valores são uma dimensão fundamental da cultura organizacional. A identidade de uma organização é moldada pela cultura, desta forma, tendo o reconhecimento e aceitação dos clientes internos e externos que percebem sua vital importância. Neste sentido, a cultura organizacional pode ser aprendida, transmitida e partilhada e, desta forma, exprime a identidade da organização, que por fim permite uma possível avaliação que auxilia na tomada de decisões.

De acordo com Tamayo (1999), proporcionar o desenvolvimento dos processos organizacionais e das pessoas conhecendo a real percepção que os membros possuem sobre os valores organizacionais é fundamental para que as organizações possam elaborar estratégias para o desenvolvimento e a manutenção de um ambiente de trabalho. A percepção humana é muito importante na Gestão de Pessoas, pois é o processo pela qual os indivíduos tomam conhecimento de si, dos outros e do mundo a sua volta, esse processo contribui para o melhor entendimento de certas características, comportamentos, 
costumes, valores etc., dos grupos existentes nas relações organizacionais. A importância atribuída por uma organização a certos valores pode determinar a quantidade de esforço investida por seus membros na emissão de certos comportamentos, bem como a sua persistência na execução dos mesmos.

Os valores organizacionais possuem três dimensões, segundo Tamayo \& Gondim (1996), cognitiva, motivacional e estruturante. A dimensão cognitiva é a forma de conhecer a realidade organizacional, expressa respostas prontas e privilegiadas a problemas organizacionais e apresenta como modelos as soluções ou os comportamentos que deram certos na empresa. Na dimensão motivacional, os valores podem motivar o indivíduo a agir, dando a sua ação a direção e intensidade emocional. Por fim, na dimensão estruturante, os valores orientam e guiam o comportamento dos membros, fornecendo um senso de direção comum a todos.

Tamayo e seus colaboradores no Brasil foram os primeiros a realizarem estudos quantitativos visando mensurar a percepção dos valores organizacionais e sua relação com a cultura organizacional. Estes criaram instrumentos tais como: a Escala de Valores Organizacionais, o Inventário de Valores Organizacionais e, mais recentemente, o Inventário de Perfil de Valores Organizacionais - IPVO, com a finalidade de estabelecer uma medida da percepção dos valores organizacionais, tendo como base o modelo de valores básicos proposto por Schwartz (1992).

A “Escala de Valores Organizacionais”, um instrumento de avaliação de percepção destes valores, criado e validado por Tamayo \& Godim (1996, p.66), foram listados trinta e três valores: eficácia, eficiência, qualidade, produtividade, comprometimento, planejamento, pontualidade, competência, dedicação, abertura, coleguismo, amizade, cooperação, criatividade, democracia, benefícios, flexibilidade, competitividade, sociabilidade, tradição, hierarquia, incentivo à pesquisa, integração Inter organizacional, modernização de recursos materiais, probidade, respeito, reconhecimento, qualificação dos recursos humanos, polidez, honestidade, plano de carreira, harmonia e justiça. Com base nessa escala é possível estabelecer uma unidade de mensuração para analise da Cultura Hierárquica, Cultura Grupal, Cultura de Mercado e Cultura de Inovação, dando uma pontuação a cada valor, se faz necessária uma pesquisa para avaliar qual a pontuação que as pessoas envolvidas no serviço dão aos valores, são formas de se medir, como por exemplo, 
pontuar cada valor de I a ıo, ou avaliar por grau de satisfação, por exemplo, Ruim, Regular, Bom e Ótimo, dentre outras maneiras que for mais conveniente para análise e com isso utilizar as ferramentas matemática (média, percentual), estatística (amostra, desvio padrão, amplitude) e informática (tabelas, gráficos) para auxiliar no entendimento e influência desses valores na prestação do serviço, analisando a quantidade, frequência e intensidade, requer uma análise contínua e constante, em períodos diferentes, e não esporadicamente, para obter resultados mais eficientes e eficazes dos valores, proporcionando um diagnóstico claro e preciso que auxiliam a tomada de decisão, ajudando a desenvolver novas estratégias de melhoria e maior competitividade.

\section{CONSIDERAÇÕES FINAIS}

O desenvolvimento econômico trouxe maior importância para o setor de serviços, com isso se faz necessário uma avaliação do papel central que a prestação de serviços exerce nos negócios, entendendo sua natureza e identificando suas características, peculiares a cada atividade, que interferem nas operações de serviços, pois dependem de vários fatores que influenciam. Todavia, os desafios são constantes nesse setor, por sua característica dinâmica, o que requer cada dia mais o entendimento dessas mudanças e dos personagens envolvidos nesse processo, para melhor se adaptar ao ambiente e garantir maior competitividade.

A avaliação estratégica na prestação de serviços requer a utilização de métodos qualitativos e quantitativos que auxiliam positivamente o processo de tomada de decisão, alinhados a missão, valores e visão da organização, porém não é uma tarefa simples, se faz necessário à escolha de ferramentas e técnicas que possibilite mensurar o processo operacional no serviço prestado desde o início até o fim, no entanto, tais ferramentas e técnicas precisam ser racionais, objetivas e precisas, mas também, claras e de fácil compreensão, devem melhor se encaixar com a cultura da organização, ou seja, seu perfil corporativo. A utilização bem sucedida pode resultar numa solução oportuna, exata, flexível, econômica e confiável.

O desempenho de uma organização prestadora de serviço é normalmente avaliado por indicadores, atrelados a números, como por exemplo, uma instituição de ensino que avalia seus alunos através de provas e a estes é atribuída uma nota, a mesma, também, é 
avaliada por autarquias competentes onde a qualidade do ensino e da instituição educacional é medida pela pontuação mínima e máxima atingida, com base em valores organizacionais, ou seja, características de caráter geral ou específico na prestação de serviços, são comportamentos que determinam a maior ou menor importância de elementos, fatos e fenômenos de acordo com o grau de importância dado por cada organização em determinado contexto ou época que acontece, agregando valor ao seu processo. Deste modo, é relevante ter consciência de que todas as organizações podem se beneficiar através desta prática, bem como os clientes, os fornecedores e os sócios, agindo dentro dos padrões sistêmicos, ela só tende a crescer, desde sua estrutura em si, mas principalmente em importância, construindo e imprimindo uma imagem sólida e transparente.

Os referenciais tangíveis são importantes, todavia, os intangíveis, característico da prestação de serviços decidem a preferência e garantem a continuidade quando avaliados estrategicamente, sistematicamente e continuamente, fazendo uma triangulação das informações obtidas e analisando os impactos das variáveis dos valores organizacionais no processo operacional, econômico, comportamental e outros.

\section{REFERÊNCIA BIBLIOGRÁFICA}

DONABEDIAN A. The seven pillars of quality. Arch Pathol Lab Med; I990; II4:1115-8.

FITZSIMMONS, James A.; FITZSIMMONS, Mona J. Administração de Serviços: Operações, estratégias e tecnologia da informação; tradução: Lene Leblon Ribeiro; revisão técnica: Gustavo Severo de Borba. - 6. Ed. - Porto Alegre: Bookman, 2010. 584 p.

GEISLER, Eliezer. The Metrics of Science and Technology. Connecticut: Quorum, 2000.

GRONROOS, Christian. Service Management and Marketing, Lexington Books, Lexington, Mass, 1990, p. 2.

GUERREIRO, Reinaldo. Modelo conceitual de sistema de informação de gestão econômica: uma contribuição à teoria da comunicação da contabilidade. 1990. 15op. Tese (Doutorado em Contabilidade e Controladoria). Universidade de São Paulo. São Paulo, 1989.

http://www.significados.com.br/mensuracao/ (acessado em I4 de novembro de 2015 as 15:02) 
LOVELOCK, Christopher; WRIGHT, Lauren. Service Marketing: People, Technology, Strategy, 6th Ed., Upper Saddle River, NJ; Prentice-Hall, 2007, p. 6.

PALADINI, Edson Pacheco; Avaliação Estratégica da Qualidade. 2ª Ed. Atlas, 2oII

RUIZ, FERNANDO MARTINSON Pesquisa Qualitativa e Pesquisa Quantitativa: Complementaridade Cada Vez Mais Enriquecedora; Adm. de Emp. em Revista, Curitiba, n. 3, p. 37-47, 2004 .

RENDER, B.; STAIR JÚNIOR, R. M.; HANNA, M. E. Análise qualitativa para administração: com Excel e POM-QM para Windows. Io. Ed. - Porto Alegre: Bookman, 2010. $776 \mathrm{p}$.

ROZADOS, H. B. F. Revista Digital de Biblioteconomia e Ciência da Informação, Campinas, v. 3, n. I, p. 6o-76, jul./dez. 2005-ISSN: 1678-765X)

TAMAYO, A. Valores Organizacionais: sua relação com satisfação no trabalho, cidadania organizacional e comprometimento afetivo. Revista de Administração, São Paulo v. 33, n.3, p. 56-63, julho/setembro, 1998.

TAMAYO, A. Valores e Clima Organizacional. In: Tamayo, Á., Paz, M.G.T. (Orgs). Escola, Saúde e Trabalho: estudos psicológicos. Brasília: UNB. 1999.

TAMAYO, A., \& GONDIM, M. G. C. Escala de valores organizacionais. Revista de Administração da USP, 31(2), 62-72. 1996.

VALERIE A. Zeithaml Mary Jo Bitner, Services Marketing, MacGraw-Hill, New York, p. 5, 1996.

XXVI ENEGEP - Fortaleza, CE, Brasil, 9 a il de Outubro de 2006; Abordagem quantitativa, qualitativa e a utilização da pesquisa ação nos estudos organizacionais; Ana Cláudia Fernandes Terence (UNESP/FCAV); Edmundo Escrivão Filho (USP/EESC). 